\title{
Study on shelf life of non-preservative containing mango drinks produced in Dhaka, Bangladesh
}

\author{
Md. Mehadee Hasan and Md. Shahidul Kabir ${ }^{\ddagger}$ \\ Department of Microbiology, Stamford University Bangladesh, 51 Siddeswari Road, Dhaka 1217, \\ Bangladesh
}

Received 20 May 2014/Accepted 17 August 2014

\begin{abstract}
This study was carried out to determine shelf life of aseptically filled non-preservative containing mango drinks. Microbiological sterility was considered as the parameter for determining the shelf life of those samples as they were aseptically filled non-preservative containing sterile mango drinks. Samples were randomly collected from 30 different batches for shelf life assay. All samples (100\%) were found to remain sterile up to 4 months. $70 \%$ of total samples showed no growth of microorganisms up to 5 months. 33.3\% of total samples showed microbial growth after 6 months. Only 6.7\% of total samples demonstrated no growth of microorganisms up to 7 months following manufacture. This study demonstrates that minimum shelf life of aseptically filled non-preservative containing mango drinks was 4 months and they may be considered safe if they are consumed within this period of time. If these drinks are taken after $\mathbf{4}$ months will bear the risk of foodborne infection and outbreak of diseases.
\end{abstract}

Key words: Mango drink; Shelf life; Non-preservative

The consumer demand of mango drinks is increasing day by day with the increase in the world population. Mango is one of the most popular and valued fruit in tropical countries and many parts of the world. They belong to the genus Mangifera indica of Anacardiaceae family. Mango is a cherished fruit which bears valuable nutrients that benefit human health (1). Mango fruits are good source of energy, vitamins A, vitamin $\mathrm{C}$, iron and phosphorus (2). They may serve source of iron and enhance production of blood. They are often suggested as supplementary source of iron in women during menstruation, pregnancy and treatment of anemia. They may provide important electrolytes such as potassium and magnesium to people who suffer from muscle cramps, stress and heart problems. Mango fruits have also been used for the treatment of nephritis as well as other kidney troubles (3).

Mango falls under the category of perishable fruits and cannot be stored for long time. Consequently, they are consumed in ample amount as fresh fruit during season. It is therefore, necessary to process mango fruits to make juices, drinks, jams, squashes, nectars, chutney, pickles, toffees and canned mango slices so that they may be consumed during the other seasons of the year. Mango drinks are sold in different forms such as, glass bottle, Polyethylene Terephthalate (PET) bottle and

${ }^{\ddagger}$ Corresponding Author: Mailing address. Dr. Md. Shahidul Kabir, Departmen of Microbiology, Stamford University Bangladesh, 51 Siddeswari Road, Dhaka 1217, Bangladesh; E-mail: mskabir@yahoo.com. tetra-packs. Among these types of packaging, PET bottled drinks are sold in large quantity in Bangladesh (4). Both preservatives and Non-preservatives mango drinks are sold in different markets in Bangladesh. However, shelf lives of non-preservative containing mango drinks are relatively shorter than those containing preservatives. Shelf life of mango drinks also depends on some other factors like packaging of drinks, storage condition, microbial population and load, $\mathrm{pH}$ and quality of raw material. Generally yeast and Zygosaccharomyces bailii are the key spoilage organisms because of their survival ability and resistance to organic acid present in fruit juice and drinks (5). Microbial growth and spoilage of mango drinks during the shelf life can pose hazards to the health of children as well as grown up people. There are several reports of illnesses due to the food borne diseases associated with the consumption of fruit juices at several places around the globe (6-8). According to previous reports, various types of juices have been shown to be contaminated by pathogenic bacterial species which includes: Escherichia coli, Salmonella spp., Shigella spp., and Staphylococcus aureus (9-11). Contaminated water used during preparation of fruit juice may cause contamination of juice by adding pathogenic microorganisms and indicator bacteria such as, coliforms, faecal coliforms and faecal streptococci (12). Growth of potentially pathogenic bacteria, yeasts and molds in mango drinks may cause deterioration and spoilage of fruit juice and drink. Fruit juice produced in the industry 
industry following standard procedure and guidelines are less likely to be contaminated and support growth of microorganisms. This study was conducted to determine the shelf life of non-preservative containing mango drink produced in Dhaka city, Bangladesh.

\section{MATERIALS AND METHODS}

Production of mango drink. Mango were purchased during the season and processed for preparation of juice and drinks by Akij Foods and Beverage Limited in Dhaka, Bangladesh. Briefly, mango pulps were aseptically prepared and pasteurized for downstream processing and packaging in different forms of juice and drinks (Figure 1). Mango drinks were prepared in batches and their microbiological quality and shelf life were checked before they were distributed to the market.

Sampling. A total of 6600 bottles of finished mango drinks in $250 \mathrm{ml}$ PET bottle manufactured between March 2013 and May 2013 were included in this study. Single sample, randomly collected from 30 batches from aseptic manufacturing and filling area, was subject to microbiological analysis for determination of shelf life.

Microbial analysis. Sterility test was performed in a sterility test room of Microbiology laboratory of Akij Foods and Beverage Limited in Dhaka, Bangladesh to determine the shelf life of all samples collected from 30 batches. First sterility test of a batch was performed within 24 hours of production and rest of the samples of the same batch were stored at room temperature for subsequent sampling to be done in one month interval from storage until the sterility test fails for a particular batch (Figure 2). Any sample failing the sterility test was considered as the end of shelf life of that batch. $250 \mathrm{ml}$ of mango drink was added to double strength $250 \mathrm{ml}$ of Trypticse Soya Broth (TSB, Oxoid, UK) and Fluid Thioglycolate Medium (FTM, Oxoid, UK) separately for sterility testing of the samples belongs to all batches. FTM was incubated at $(32.5 \pm 0.2){ }^{\circ} \mathrm{C}$ temperature and TSB was incubated at $(22.5 \pm 0.2){ }^{\circ} \mathrm{C}$ temperature for 14 days following the standard operating procedure of the company. Same procedures were followed for all 30 batches.

\section{RESULTS AND DISCUSSION}

Mango drinks from 30 different batches were tested for sterility in every month following their production. No microbial growth was observed in any of the samples tested from all 30 batches (100\%) up to 4 months in this study. 11 batches $(36.7 \%)$ were found to be contamination up to 7 months. According to this study the shelf life of aseptically filled preservatives free mango drinks should be 4 months. After four months of incubation fruit drinks apparently supported growth of microorganisms and some of the batches $(11,36.7 \%)$ showed growth of microorganisms and lost their sterility. Microorganisms can utilize the chemical ingredients of mango drinks and change their organoleptic property. Growth of pathogenic microorganisms in food or drink poses the risk of outbreak of disease in the community. So, it is likely that mango drinks may deteriorate at any time after 4 months of manufacture and become unsuitable for consumption. Amazingly, some of the batches (6.7\%) showed no growth even after 8 months. It is not clear from this study as to why there was such difference in the shelf life in different batches and requires further investigation.

Physicochemical parameters play an important role in

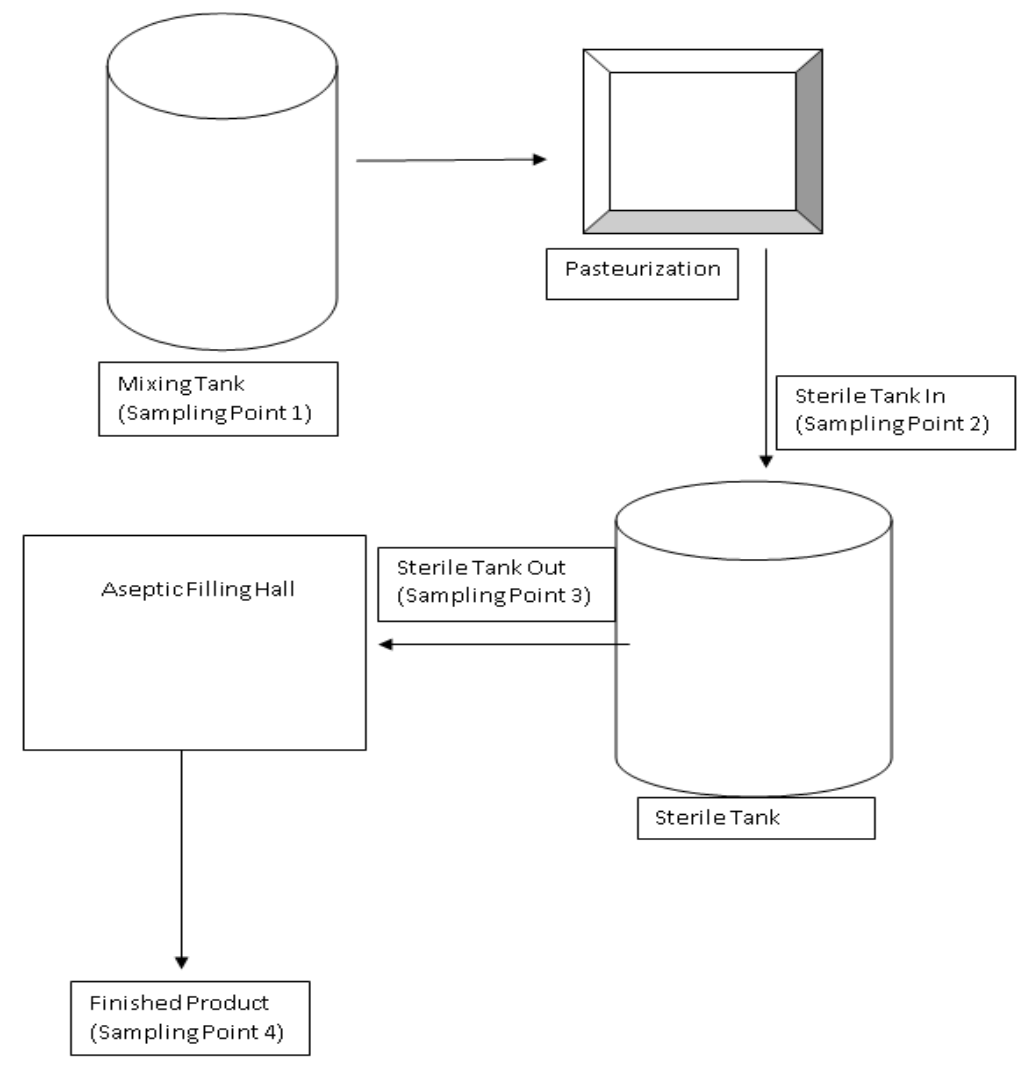

FIG. 1. Schematic diagram of production plant used for preparing mango drink 


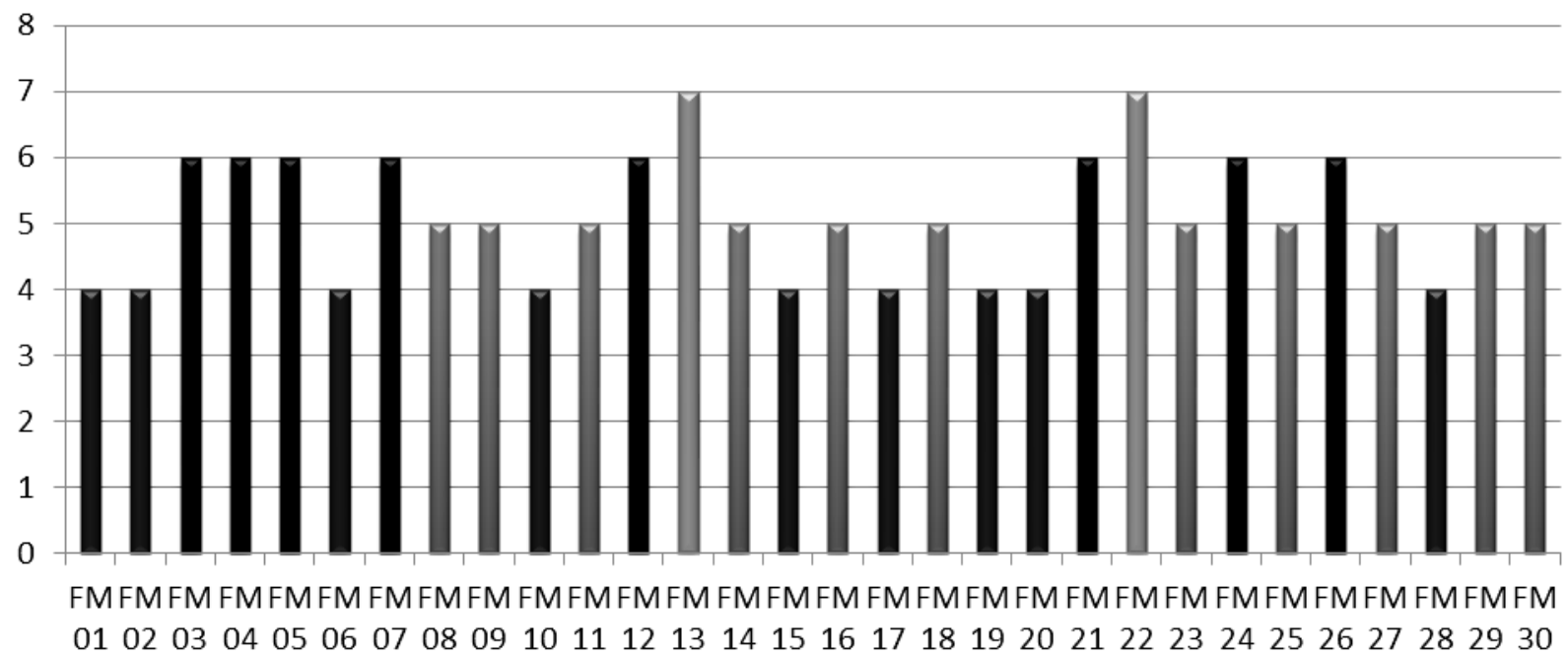

FIG. 2. Shelf lives of aseptically filled individual mango drink samples

the preservation of fruit juice and drinks. Fruit drinks may be contaminated at any stage of production starting from the raw materials to the finished product. Growth of microorganisms in fruit drinks will depend on the level of microbial load during production, contamination at a later stage such as, packaging, storage and handling. Temperature, time of storage, type of mango used may also be crucial for maintaining the shelf life of the products. As a whole, standard procedure and guidelines should be followed during preparation of food and beverage. People in the developed countries follow the food laws and regulations more sincerely than those in the developing and underdeveloped countries. This indifferent attitude towards following the food laws is a matter of concern in developing countries like Bangladesh.

A number of preservatives for example, citric acid, sorbic acid, benzoic acid, erythorbic acid and other artificial chemicals are used to enhance shelf life of juice and drinks. Some of the fruits may possess organic acids such as, citric acid, malic acid, oxalic acid and tartaric acid which may act as natural preservatives for fruit juice and drinks and eliminate the necessity of adding artificial preservative. However, addition of excess amount of citric acid and malic acid will increase the shelf life of pulp as well as enhance the flavour, aroma and taste of the product. These organic acids generally lower the $\mathrm{pH}$ and inhibit the growth of microorganisms and stop spoilage of fruit drinks (1315). A number of functional groups such as; carboxyl and hydroxyl may affect the activity of organic acids (15-19). In the presence of more than one organic acid, it will be difficult to single out the role of a particular organic acid in preservation of fruit drink. However, the relative concentration of different organic acids will affect the sensorial characteristic, $\mathrm{pH}$, total acidity, microbial load, sweetness and acceptability of fruit juice and drinks (13-14, 17).

No preservative was deliberately added for preservation of mango drinks samples which were included in this study. Apparently, organic acids naturally present in mango worked as preservatives in mango drinks. Aseptic technique, clean room and pasteurization processes used during manufacture of fruit drinks were effective in terms of controlling the growth of microorganisms for at least 4 months. Some of the batches showed longer shelf life than the other, which may be due to the variation in the quality of raw materials, efficiency of pasteurization and preservation condition of mango drinks. The shelf life generally declared for these products were 6 months which is a bit contradictory to the finding of this study and suggests addition of suitable preservative to enhance the shelf life of the mango drinks. This will facilitate safe distribution of mango drink in the marketing chain and reduce the risk of contamination and spoilage of the product before the expected expiry date of 6 months.

\section{ACKNOWLEDGEMENTS}

Authors thank Akij Food and Beverage Ltd. for providing laboratory facilities to carry out the experiments of present study.

\section{REFERENCES}

1. Suaads, A., and E. A. Hamed. 2008. Microbial growth and chemical analysis of Bottled fruit juices and drinks in Riyadh, Saudi Arabia. Res. J. Microbiol. 3: 315-325.

2. Malik, M. A., A. Salam, and M. Saleem. 1994. Mango Products. In A. Saeed (ed.), Mango and summer fruits of Pakistan. A Brochure of the Hort. Foundation Pak., Islamabad.

3. Islam, N. U. 1986. Some physico-chemical studies on the mango pulp stored in glass bottles. M. Sc. thesis, Dept. of Food Tech., Uni. of Agri., Faisalabad.

4. Annual Progress Report. 2013. Akij Food and Beverage Ltd. Available at: https://www.scribd.com/doc/118959623/Report-on-Akij-Group. Accessed 5 April, 2014. 
5. Stratford, M., and S. A. James. 2003. Spoilage yeasts with emphasis on the genus Zygosaccharomyces, p. 171-191. In T. Boekhout, and V. Robert (ed.), Yeasts in food - Beneficial and detrimental aspects. Woodhead Publishing Ltd. and CRC Press, Cambridge.

6. Mosupye, F. M., and V. A. Holy. 2000. Microbiological hazard identification and exposure assessment of street food vending in Johannesburg, South Africa. Int. J. Food Microbiol. 61: 137-145.

7. Muinde, O. K., and E. Kuria. 2005. Hygienic and sanitary practices of vendors of street foods in Nairobi, Kenya. African J. Food Agri. Nutrition Dev. 5 (1): 1-13.

8. Chumber, S. K., K. Kaushik, and S. Savy. 2007. Bacteriological analysis of street foods in Pune, Indian J. Public Health. 51 (2): 114-6.

9. Buchaman, R. L., S. G. Edelson, R. L. Miller, and G. M. Sapers. 1999. Contamination of intact apples after immersion in an aqueous environment containing Escherichia coli O157:H7. J. Food Prot. 62: 444-450.

10. Sandeep, M., A. Diwakar, and G. Abhijit. 2004. Microbiological analysis of street vended fresh squeezed carrot and kinnow-manderian juices in Patiala city, India. Internet J. Food safety. 3: 1-3.

11. Barro, N., et al. 2006. Hygienic status and assessment of dishwashing waters, utensils, hands and pieces of money from street food processing sites in Ouagadougou (Burkina Faso). African J. Biotechnol. 5 (11): 11071112
12. Tasnim, F., et al. 2010. Quality Assessment of industrially processed fruit juices available in Dhaka city, Bangladesh. Mal. J. Nut. 16 (3): 431-438.

13. Pao, S., and P. D. Petracek. 1997. Shelf life extension of peeled oranges by citric acid treatment. Food Microbiol. 14: 485-491.

14. Chang-ping, H., and J. K. Siebert. 1999. The inhibitory effect of acids on microbial growth has long been used to preserve foods from spoilage. Int. J. Food microbiol. 47: 189-201.

15. Durrani, Y., et al. 2011. Sensory evaluation of mango (Chaunsa) pulp preserved with addition of selected chemical preservatives and antioxidant during storage. Sarhad J. Agric. 27 (3): 471-475.

16. Chinnici, F., U. Spinabelli, C. Riponi, and A. Amati. 2005. Optimization of the determination of organic acids and sugars in fruit juices by ion-exclusion liquid chromatography. J. Food Comp. Ana. 18 (2-3): 121-130

17. Younis, M. S., et al. 2011. Effect of preservatives on physicochemical, microbial and sensory attributes of mangoes. Internet J. Food Safety 13: 246263.

18. Addo, M. G., W. G. Akanwariwiak, P. Addo-Fordjour, and K. ObiriDanso. 2008. Microbiological and sensory analysis of imported fruit juices in Kumasi, Ghana. Res. J. Microbiol. 3 (8): 552-558.

19. Gao, Z., et al. 2012. Evaluation of different kinds of organic acids and their antibacterial activity in Japanese Apricot fruits African J. Agri. Res. 7 (35): 4911-4918. 